\title{
Factors negatively influencing knowledge sharing in software development
}

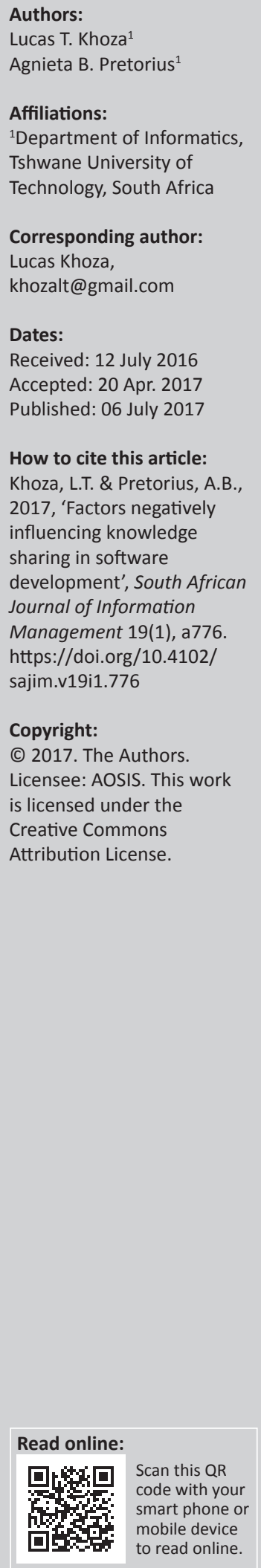

Background: 'Knowledge is power' and software developing organisations are dependent on knowledge to achieve and maintain a competitive advantage. Subsequently, knowledge sharing is a key factor for modern software developing organisations to succeed in today's competitive environment. For software developing organisations to reach their goals and objectives, knowledge sharing - and in particular the sharing of useful knowledge - needs to be targeted. To promote knowledge sharing, factors influencing knowledge sharing need to be identified and understood.

Objective: This study seeks to identify factors that negatively influence knowledge sharing in software development in the developing country context.

Method: Expert sampling as a subcategory of purposive sampling was employed to extract information, views and opinions from experts in the field of information and communication technology, more specifically from those who are involved in software development projects. Four Johannesburg-based software developing organisations listed on the Johannesburg Stock Exchange (JSE), South Africa, participated in this research study. Quantitative data were collected using an online questionnaire with closed-ended questions.

Results: Findings of this research reveal that job security, motivation, time constraints, physiological factors, communication, resistance to change and rewards are core factors negatively influencing knowledge sharing in software developing organisations.

Conclusions: Improved understanding of factors negatively influencing knowledge sharing is expected to assist software developing organisations in closing the gap for software development projects failing to meet the triple constraint of time, cost and scope.

\section{Introduction}

Knowledge is power. In today's ever-shifting competitive environment, software developing organisations are increasingly dependent on knowledge to gain and maintain an advantage over their competitors (Ghobadi \& D'Ambra 2012; Mkhize 2015; Willems 2009). Subsequently, knowledge sharing is a key factor for modern software developing organisations to succeed (Ghobadi 2015). Sharing of knowledge is required not only between members of the same project, but also within an organisation and across various organisations (Soinil, Makinen \& Tenhunen 2007). For software developing organisations to reach their goals and objectives, knowledge sharing - and in particular the sharing of useful knowledge - needs to be promoted and facilitated (Ghobadi 2015; Jinming \& Yuntao 2011). To advance knowledge sharing, factors influencing knowledge sharing (positively and negatively) need to be identified and understood. All types of knowledge that need to be shared must be managed by its stakeholders and, therefore, to make knowledge sharing in organisations more effective, strategies for knowledge management must be employed to ensure that useful knowledge is shared. A multitude of publications have been constructed on knowledge sharing to enhance project success (Cuellar 2010; Ghobadi \& Mathiassen 2016; Jari, Timo \& Vesa 2007; Park \& Lee 2014; Soinil, Makinen \& Tenhunen 2007). However, many individuals in organisations are still not able and/or willing to share their knowledge, especially so if they fear that it would reduce their worth in the organisation (Willems 2009). The promotion of knowledge sharing is problematic where factors negatively influencing knowledge sharing are not known to the software developing organisation (Ghobadi 2015; Kukko \& Helander 2012; Riege 2005). Software developing organisations are failing to meet customers' expectations, not because they lack the necessary knowledge, skills or expertise, but because they are not fully

Note: This article is partially based on a presentation 'Factors influencing knowledge sharing in software development', given at the SAKMS (Southern African Knowledge Management Summit), 10-12 May 2016 at the Farm Inn, Pretoria, South Africa, available here: http://sakmsummit.net/wp-content/uploads/2016/05/2016SAKMS_Khoza_LT_Factors-influencing-knowledge-sharing-in-softwaredevelopment.pdf 
aware of factors influencing the sharing of useful knowledge (Killingsworth, Yajiong \& Yongjun 2016). The success of knowledge sharing is to a large extent determined by the factors influencing knowledge sharing, and therefore those factors must first be known, analysed and understood (Chatterjee 2014). When knowledge is shared among team members, the probability of project success increases, for example, in terms of time, budget and scope (Cuellar 2010).

Limited empirical studies are available that investigate challenges related to the sharing of knowledge within software development projects in developing countries (Mansooreh, Mojtaba \& Muhammad 2016). This research study investigates factors that negatively influence knowledge sharing in software developing organisations. The study is expected to contribute to the existing body of knowledge by providing empirical data on factors that negatively influence knowledge sharing in software developing organisations in a developing country context. Furthermore, the study serves by highlighting the factors that software developing organisations should focus on when rolling out efforts to promote knowledge sharing.

\section{Conceptual framework}

The research discussed in this article is part of a broader study (refer to Figure 1) that explores knowledge sharing in software developing organisations with focus on: (1) kinds of knowledge considered useful to share, (2) ways of sharing useful knowledge, (3) useful knowledge currently shared and (4) factors negatively influencing the sharing of useful knowledge. Useful knowledge to be shared can be tacit or explicit (Jashapara 2011) and can be shared either through social interaction or through codification (Willems 2009). This article only focuses on factors influencing knowledge sharing in software developing organisations, especially those that negatively affect knowledge sharing.

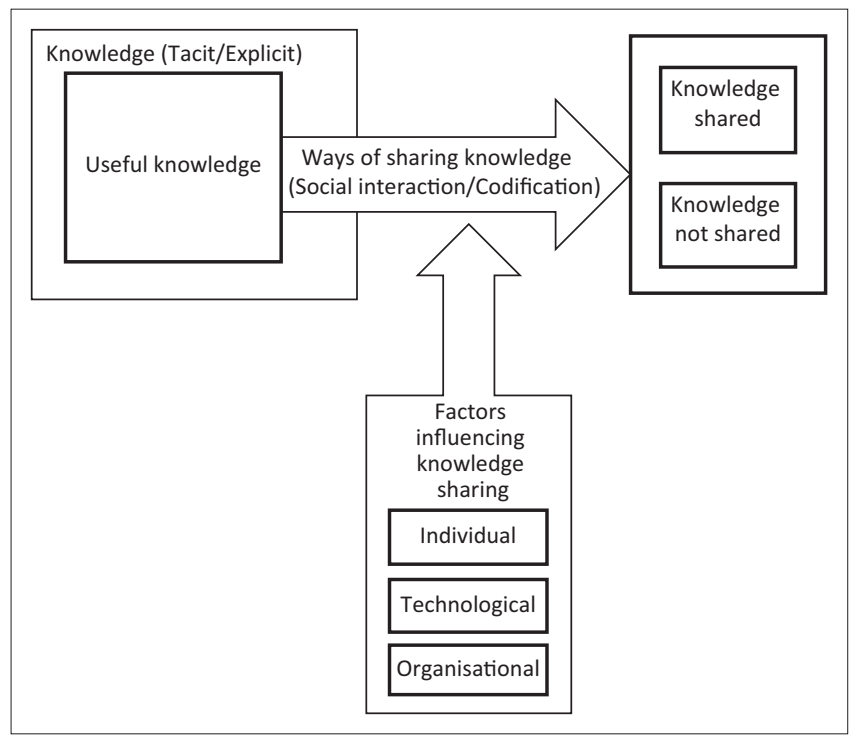

Source: Adapted from Willems, R., 2009, 'Knowledge sharing and retention through the us of collaborative software', Bachelor's thesis, Radboud University Nijmegen, the Netherlands FIGURE 1: Framework for knowledge sharing in software development.
Note that the distinction between tacit and explicit knowledge and between knowledge sharing through social interaction and through codification is not central to the purpose of this research study. In fact, knowledge sharing often involves elements of both tacit and explicit knowledge (Jashapara 2011).

Perceived importance of factors negatively influencing knowledge sharing is investigated in three categories, as classified by Riege (2005) and Kukko and Helander (2012): Individual factors, technological factors and organisational factors. Individual factors are between people either in the same team or in cross functional teams or organisations caused by their perceptions and beliefs. The adoption of new technology and change is a problem; therefore, technology plays a major role in the knowledge sharing process (Riege 2005). Some team members as a result of their unfamiliarity with the existing technology in the organisation find it difficult to make use of it. It is not surprising that most literature reveals culture as one of the barriers linked to the organisational factors. If the environment within the organisation is not conducive enough for knowledge sharing, then it becomes difficult for employees to share their knowledge (Kukko \& Helander 2012; Riege 2005).

To address individual factors influencing knowledge sharing, pair programming, daily scrum meetings and project retrospectives can be used (Ghobadi \& Mathiassen 2015), and this will leverage relationships and strengthen project resources among team members (Ghobadi \& Mathiassen 2016). When doing pair programming, it is recommended to pair senior and junior employees as a process of sharing knowledge to the younger generation. Technological factors can be addressed by creating network groups where team members can share their ideas in the comfort of their devices (Ghobadi \& Mathiassen 2015). The study is expected to contribute towards closing the gap that causes software development projects failing to meet the triple constraint of time, cost and scope by aiding with the understanding of factors negatively influencing knowledge sharing. The elements of the triple constraint mentioned earlier (time, scope and cost) are dependent on one another. For instance, when a project's cost is reduced, either the scope must be reduced or the time must be increased. When the project's time is reduced, either the cost must be increased or the scope must be reduced. When the project's scope is increased, either the cost or time must be increased (Cuellar 2010). In order for software development projects to be successfully delivered within this triple constraint, project team members must adopt some knowledge sharing strategies, which might help in knowledge management and in solving problems. By doing so, it is expected to contribute to the body of knowledge on knowledge sharing in software development.

\section{Literature review}

Although knowledge is regarded as an important asset in software development projects, it has its own obstacles. Zhang, Yezhuang and Zhongying (2006) and Ghobadi (2015) point out that factors influencing knowledge sharing differ 
with regard to three aspects: culture, management and technology. These three obstacles of knowledge sharing result in a high cost and low income. Knowledge sharing comprises many factors and boundaries within organisations. In today's organisations, knowledge sharing is given more attention as a way of improving project success; however, software developing organisations are experiencing difficulties when trying to share knowledge without understanding the factors that negatively influence knowledge sharing (Ghobadi 2015; Kukko \& Helander 2012; Riege 2005). For the success of projects, the utilisation of existing knowledge is crucial as this enhances the organisation's core competencies. Software developing organisations should continue encouraging project team members to realise the benefits of knowledge sharing (Min, He \& Gan 2010). Ghobadi (2015) identifies seven knowledge sharing barriers in software projects: technology-related, diversity-related, capability-related, team perceptions, team organisation, organisational practices and task-related barriers. Of all drivers or factors identified in this research study and for the purpose of this study, the researchers focus on three categories (individual, technological and organisational) as classified by Riege (2005) and Kukko and Helander (2012). Literature reveals that common factors negatively influencing knowledge sharing such as top management support, lack of time, job security, organisational culture and reluctance to use technology exist across different teams and projects with specific factors that are only evident for specific teams such as agile teams and global distributed teams (Ghobadi 2015).

To make knowledge sharing more effective, knowledge management is key (Ghobadi \& D'Ambra 2012). All types of knowledge that need to be shared must be managed by its stakeholders. In the process of managing knowledge, one of the key issues to be considered is the process of knowledge sharing within and across software developing organisations (Jinming \& Yuntao 2011). How employees perceive the process of knowledge sharing is influenced by the culture of the organisation and the benefits thereof. Good relationships and trust must be built among employees, because some employees find it difficult to share their knowledge with employees whom they do not trust or have no good relationship with (Juan, Rong, Song \& Weili 2009).

The main aim of knowledge sharing in software development is to solve problems in information technology (IT) projects in a faster and cheaper way than when knowledge is not shared (Ghobadi \& D'Ambra 2012; Kukko \& Helander 2012). Andrawina (2009) asserts wide recognition of the leading role of knowledge as an investment to gain reasonable benefit. Knowledge is regarded as the most valuable resource for learning better ways of performing tasks, solving complexities within workloads and introducing new ways of solving problems (Chatterjee 2014). The ability of organisations to meet their client's expectations and to be regarded superiorly competitive depends entirely on their ability and speed of grabbing new opportunities and on their employees' sharing of knowledge effectively and efficiently. Knowledge is classified into two types: tacit and explicit knowledge
(Jashapara 2011). Knowledge types exhibit essential roles in the knowledge sharing process (Jashapara 2011). Knowledge sharing improves knowledge capital in organisations and promotes project success as knowledge sharing is all about adding value to the organisation and improving success (Ghobadi \& D'Ambra 2012). In today's ever-changing competitive environment, an organisation's success depends largely on its ability to share knowledge successfully and efficiently. Knowledge sharing is not only required between team members involved in a project, but also between projects in an organisation and across different organisations (Ghobadi \& D'Ambra 2012; Soinil, Makinen \& Tenhunen 2007). Members from different cross functional groups will bring their expertise and knowledge to share with each other, and this will improve project success (Ghobadi \& D'Ambra 2012).

For the process of knowledge sharing to be a success in IT projects, Chatterjee (2014) stresses the need for middle managers to become involved in the management of knowledge sharing processes within organisations. If managers take part in the process of knowledge sharing, they will be able to monitor such sharing, ensuring that all employees acquire the necessary skills and expertise for the success of the organisation (Chatterjee 2014). Middle managers must be the first people to motivate employees to share knowledge as they always work closely to project team members; they must understand how to manage knowledge, to encourage employees and to build a good relationship with them so that good relationships may also be built between employees (Chatterjee 2014).

Relationships between the use of IT services, information security, trust, intentions of knowledge sharing and behaviour must be discussed within and across organisations (Ghobadi 2015; Juan et al. 2009). According to Mohammad and Rajib (2014) and Ghobadi (2015), there are six ways of knowledge sharing for software developing organisations: pair programming, comments are made when coding informing other users on what has changed; release and sprint panning; customer collaboration; different teams working together; everyday team (scrum) meetings; and project presentations (retrospectives) for lessons learnt.

The above ways of sharing knowledge are more effective for small teams because they rely mostly on face-to-face collaborations among team members (Mohammad \& Rajib 2014). However, for large teams, knowledge may be shared via wikis, video conferencing, chat rooms and online conferencing.

Malin (2012) emphasises the study of Mohammad and Rajib (2014) on the ways of successfully sharing knowledge in software development projects, mentioning the following:

- pair programming

- postmortem analysis (PMA) or retrospectives: capturing lessons learnt in software projects

- daily scrum meetings 
- observation

- imitation and practice.

Zhang and Jiang (2012) describe two ways of sharing knowledge: responsive knowledge sharing, where individuals use this method to share knowledge in order to gain organisational characteristics, interpersonal characteristics, individual characteristics and perceived nature of knowledge; and proactive knowledge sharing where the individual who shares knowledge is seeking certain pertinent comments and feedback from those who received the knowledge, in order to gain more understanding, insight and value from the knowledge shared. In the process of knowledge sharing, it is important for both parties - the sharer of the knowledge and the receiver - to be honest and trustworthy in offering feedback where necessary in order to build a good relationship between them (Zhang \& Jiang 2012). It is clear that when individuals share their knowledge, they expect certain future benefits which will improve their perception of self-efficacy, gaining more understanding of the knowledge. Participants always wish to know the ways in which knowledge shared has benefited others or the organisation through feedback.
Communication is involved in the process of supplying feedback.

Table 1 summarises factors influencing knowledge sharing as proposed by various authors (Alony \& Whymark 2006; Biggam 2002; Jinming \& Yuntao 2011; Keyes 2008; Kukko \& Helander 2012; Paulin \& Suneson 2012; Riege 2005). Knowledge sharing obstacles may be categorised into three levels: (1) the individual level - which refers to the place in which knowledge is vested, (2) organisational level - the level at which competitive value for organisational success is accomplished, and (3) the technological level - the level at which technology is used in the process of knowledge sharing (Kukko \& Helander 2012; Riege 2005). Various authors categorise factors influencing knowledge sharing into different levels or categories. However, all factors fall within the three categories as proposed by Riege (2005) and Kukko and Helander (2012).

For organisations to reap the benefit from knowledge management, such as improved customer relations, reduced cost, employee learning, satisfaction and retention, they need

TABLE 1: Factors influencing knowledge sharing.

\begin{tabular}{|c|c|c|}
\hline Variable & Factors & Authors \\
\hline \multirow[t]{15}{*}{ Individual } & Lack of time & Riege (2005); Kukko and Helander (2012); Keyes (2008) \\
\hline & Lack of trust & Riege (2005); Kukko and Helander (2012); Jinming and Yuntao (2011); Alony and Whymark (2006) \\
\hline & Little realisation of what is known & Riege (2005); Kukko and Helander (2012); Jinming and Yuntao (2011) \\
\hline & Power relationships & Riege (2005); Kukko and Helander (2012); Keyes (2008) \\
\hline & Personal characteristics & Riege (2005); Kukko and Helander (2012); Jinming and Yuntao (2011) \\
\hline & Psychological factors & Jinming and Yuntao (2011) \\
\hline & Capability factors & Jinming and Yuntao (2011) \\
\hline & Cognitive factors & Jinming and Yuntao (2011) \\
\hline & Resistance to change & Biggam (2002) \\
\hline & Attitudes & Paulin and Suneson (2012) \\
\hline & Tie properties & Alony and Whymark (2006) \\
\hline & Perceptions & Paulin and Suneson (2012) \\
\hline & Job uncertainty & Jinming and Yuntao (2011); Keyes (2008); Biggam (2002) \\
\hline & Lack of social networks & Alony and Whymark (2006) \\
\hline & Language problems & Riege (2005); Kukko and Helander (2012); Biggam (2002) \\
\hline \multirow[t]{11}{*}{ Organisational } & Poor organisational climate and culture & Riege (2005); Kukko and Helander (2012); Paulin and Suneson (2012) \\
\hline & Suspension of knowledge from managerial goals & Riege (2005); Kukko and Helander (2012) \\
\hline & $\begin{array}{l}\text { Neglect of managerial communication on the benefits of } \\
\text { knowledge sharing }\end{array}$ & Riege (2005); Kukko and Helander (2012); Paulin and Suneson (2012) \\
\hline & Distance & Riege (2005); Kukko and Helander (2012); Alony and Whymark (2006) \\
\hline & Management support & Alony and Whymark (2006) \\
\hline & No technique used for knowledge sharing & Riege (2005); Kukko and Helander (2012) \\
\hline & Lack of reward systems & $\begin{array}{l}\text { Riege (2005); Kukko and Helander (2012); Paulin and Suneson (2012); Keyes (2008); Alony and } \\
\text { Whymark (2006); Biggam (2002) }\end{array}$ \\
\hline & Effectiveness of diverse divisions & Riege (2005); Kukko and Helander (2012) \\
\hline & Complexity of different organisations & Riege (2005); Kukko and Helander (2012); Ghobadi (2015) \\
\hline & Team culture & Keyes (2008); Ghobadi (2015) \\
\hline & Lack of network connections & Riege (2005); Kukko and Helander (2012); Alony and Whymark (2006) \\
\hline \multirow[t]{4}{*}{ Technological } & Unsuitable technology & Riege (2005); Kukko and Helander (2012); Keyes (2008) \\
\hline & No training & Riege (2005); Kukko and Helander (2012); Keyes (2008) \\
\hline & No communication about the benefits of chosen technologies & Riege (2005); Kukko and Helander (2012); Keyes (2008) \\
\hline & Lack of time & Riege (2005); Kukko and Helander (2012); Keyes (2008) \\
\hline
\end{tabular}

Note: Please see the full reference list of the article, Khoza, L.T. \& Pretorius, A.B., 2017, 'Factors negatively influencing knowledge sharing in software development', South African Journal of Information Management 19(1), a776. https://doi.org/10.4102/sajim.v19i1.776, for more information. 
to address the effective knowledge flow among employees and should be aware of factors affecting knowledge sharing, also referred to as obstacles to knowledge sharing. The existing literature further indicates that more emphasis should be placed on cultural, organisational and technological factors as these are the main factors hindering knowledge sharing in software development projects (Ghobadi 2015; Keyes 2008). According to Hase, Sankaran and Davies (2006), the greatest obstacles to knowledge sharing are dysfunctional behaviour and organisational culture. As knowledge is believed to be power in software development projects, why would participants simply be willing to share or give it to someone else, if not motivated to do so? The resistance from culture, personal interest or from an individual's perspective form part of the obstacles to knowledge sharing. Certain knowledge users are the obstacles to knowledge sharing in the sense that they are not ready to release their knowledge, sometimes because they do not understand it, sometimes owing to security reasons and sometimes their goals conflict with organisational goals (Biggam 2002; Ghobadi 2015; Riege 2005).

\section{Research methodology}

In this section, we share the research approach, population and sampling, data collection techniques and instruments as well as methods for data analysis.

\section{Research approach}

This research study follows the quantitative methodology. Quantitative and qualitative data were gathered to construct a holistic view on factors influencing knowledge sharing in software developing organisations. Because the main questions to be answered in this research are about the what, which, how and how much of the observed phenomenon, the study is classified as following a positivism paradigm. Some qualitative data were collected through interviews to complement the quantitative data gathered through an online questionnaire. The purpose of interviews was to see if participants would add any factor that was not covered in the literature.

\section{Population and sampling}

The population of this research study comprised targeted employees of four software developing organisations listed on the Johannesburg Stock Exchange (JSE), South Africa. True to the purpose of this research study, expert sampling as a subcategory of purposive sampling was used to extract information, views and opinions from experts in the field of Information and Communication Technology (ICT), especially those who are involved in software development projects (e.g. project managers, business analysts, system testers, database administrators and programmers). Online questionnaires were distributed to 270 employees of four software developing organisations. Of the 270 employees, only $218(80.7 \%)$ had the potential to participate in the research study, having more than 1 year of experience. The remaining 52 (19.3\%) were not eligible to participate, and thus 117 (53.7\%) of the employees participated successfully in this research study. Seven interviews were conducted at Organisation A, five interviews at Organisation B and, lastly, one interview at Organisation C. Therefore, a total of 13 individuals participated in the interview process.

\section{Data collection techniques and instruments}

Data were collected using an online questionnaire consisting of closed-ended questions. Interviews were conducted with a subset of the participants who participated in the online questionnaire to extract additional information and to foster in-depth understanding of the views of participants. Note that respondents were asked to respond by indicating the level of agreement on a five-point Likert scale ranging from 'strongly agree' to 'strongly disagree'.

\section{Method for data analysis}

After data collection, data were scrutinised using the IBM Statistical Package for the Social Science (SPSS) version 20, Stata version 13 and Excel 2010. According to Greasley (2008), before data being entered into SPSS, it must be coded; this must occur before the analysis. Codes were therefore written and entered into SPSS. Data were transferred from the Excel format to the Stata V13 format, wherein statistical analysis was performed by StatTransfer. This research study was more quantitative in nature but in order to obtain more information from participants, qualitative data were collected through interviews. Qualitative data obtained through interviews supplemented the quantitative data collected through the questionnaires. No software was used to analyse interviews. Interviews were interpreted based on the responses given.

The following were tested using relevant instrument (test for association):

- whether responses to questionnaires differ significantly for the various positions or roles (e.g. business analyst, programmer, database administrator, system tester and project manager)

- whether responses to questionnaires vary significantly for different demographic variables (e.g. gender, years of experience and highest qualification).

\section{Test for internal consistency}

Descriptive statistics were generated to summarise the data for the factors influencing the sharing of knowledge. Cronbach's alpha is a statistical measure of how well a set of items are correlated (Field 2005). George and Mallery (2003), Field (2005) and Kline (1999) provide the following guidelines for Cronbach's alpha: > 0.9 - Excellent; $>0.8-$ Good; ${ }^{3} 0.7$ - Acceptable; > 0.6 - Questionable; > 0.5 - Poor; and $<0.5$ - Unacceptable. Accordingly, Cronbach's alpha, with a cut-off point of 0.7 was used to test for internal consistency. The Cronbach's alpha for the factors tested is 0.9534, suggesting that the items have a high ('excellent') internal consistency. 


\section{Research results}

In the following subsections, the results of the study are discussed relating to response rate and demographics, factors influencing knowledge sharing, tests for internal consistency and test of association.

\section{Response rate and demographics of respondents to questionnaire}

The results indicate that the majority of respondents who participated in this study were males $(n=78 ; 66.67 \%)$, while $33.33 \%(n=39)$ were females. This aligns to a study by Hans and Rwelamil (2012) affirming that ICT companies in South Africa are dominated by males. Most respondents were system testers $(n=30 ; 25.64 \%)$, and this may indicate that systems are tested thoroughly in order to avoid bugs and to deliver according to client expectations. Not far behind were programmers $(n=29 ; 24.79 \%)$, business analysts $(n=22$; $18.80 \%)$, database administrators $(n=20 ; 17.09 \%)$, project managers $(n=10 ; 8.55 \%)$ and others $(n=6 ; 5.12 \%)$. As discussed in a later section, the differences in roles to some extent explain the variance in answers between participants.

The majority of the respondents have experience of 6-10 years $(n=40 ; 34.19 \%)$, followed by those with experience between 1 and 5 years $(n=33 ; 28.21 \%)$, thereafter those with experience between 11 and 20 years $(n=29 ; 24.79 \%)$ and lastly those with 21 or more years $(n=15 ; 12.82 \%)$. These results may furthermore be an early indicator of the possibility of the years of experiences having a direct or indirect impact of the role and contribution of employees in the knowledge sharing process. Lastly, the majority of respondents have, as highest qualification, a degree or diploma $(n=69 ; 58.97 \%)$, followed by postgraduate qualifications $(n=40 ; 34.19 \%)$, matric $(n=7 ; 5.98 \%)$ and other $(n=4 ; 0.85 \%)$. In summary, these figures reveal that the majority of employees in the software developing organisations have undergraduate qualifications.

\section{Factors influencing knowledge sharing}

Table 2 shows the factors influencing the sharing of knowledge in the participating software developing organisations, sorted in descending order of the percentage of respondents who indicated that they strongly agree with the factors that influence knowledge sharing. These factors negatively affect the sharing of knowledge in software developing organisations, for example, lack of communication among team members especially those in different geographical areas. For the sake of job security, employees do not share their knowledge and this affects the organisation as

TABLE 2: Factors influencing the sharing of knowledge.

\begin{tabular}{|c|c|c|c|c|c|c|}
\hline Number & Factors & Strongly agree (\%) & Agree (\%) & Undecided (\%) & Disagree (\%) & Strongly disagree (\%) \\
\hline 1 & Job security & 65 & 21 & 8 & 3 & 3 \\
\hline 2 & Motivational factors & 61 & 27 & 8 & 3 & 1 \\
\hline 3 & Lack of time & 56 & 28 & 6 & 7 & 3 \\
\hline 4 & Psychological factors & 56 & 31 & 5 & 6 & 2 \\
\hline 5 & Lack of communication & 54 & 35 & 3 & 6 & 2 \\
\hline 6 & Resistance to change & 54 & 32 & 6 & 6 & 2 \\
\hline 7 & Lack of rewards & 51 & 34 & 6 & 8 & 1 \\
\hline 8 & Unrealistic expectation & 51 & 33 & 5 & 9 & 2 \\
\hline 9 & Education & 50 & 29 & 9 & 9 & 3 \\
\hline 10 & Lack of trust & 49 & 32 & 10 & 6 & 3 \\
\hline 11 & Lack of infrastructure & 48 & 33 & 7 & 9 & 3 \\
\hline 12 & Power relationship & 44 & 39 & 9 & 7 & 1 \\
\hline 13 & Competitiveness of units & 41 & 36 & 15 & 5 & 3 \\
\hline 14 & Disintegration of knowledge & 39 & 38 & 14 & 6 & 3 \\
\hline 15 & Poor organisational culture & 38 & 46 & 9 & 3 & 4 \\
\hline 16 & Reluctance of technology & 38 & 38 & 13 & 8 & 3 \\
\hline 17 & Distance & 38 & 27 & 15 & 16 & 4 \\
\hline 18 & No knowledge & 38 & 34 & 15 & 10 & 3 \\
\hline 19 & Age & 36 & 34 & 16 & 9 & 5 \\
\hline 20 & Personal characteristics & 34 & 52 & 9 & 5 & 0 \\
\hline 21 & Language problems & 34 & 41 & 13 & 9 & 3 \\
\hline 22 & Lack of social network & 34 & 38 & 16 & 5 & 7 \\
\hline 23 & No feedback & 34 & 39 & 15 & 7 & 5 \\
\hline 24 & Unsuitable technology & 33 & 41 & 12 & 8 & 6 \\
\hline 25 & Cultural characteristics & 33 & 45 & 11 & 6 & 5 \\
\hline 26 & Complexity of organisation & 32 & 51 & 5 & 9 & 3 \\
\hline 27 & Team characteristics & 32 & 52 & 9 & 5 & 2 \\
\hline 28 & Capability factors & 30 & 41 & 19 & 3 & 7 \\
\hline 29 & Lack of management support & 30 & 34 & 18 & 13 & 5 \\
\hline 30 & Factual knowledge & 29 & 35 & 23 & 5 & 8 \\
\hline 31 & Lack of training & 29 & 48 & 14 & 6 & 3 \\
\hline 32 & Cognitive factors & 29 & 42 & 15 & 7 & 7 \\
\hline 33 & Low awareness & 26 & 50 & 15 & 3 & 6 \\
\hline
\end{tabular}


a whole. Because of work overload, environment pressure to deliver on a timely basis, there is always a lack of time to share the existing knowledge.

Note that respondents were asked to respond by indicating the level of agreement on a five-point Likert scale ranging from 'strongly agree' to 'strongly disagree'.

Job security, motivational factors, lack of time, psychological factors, lack of communication, resistance to change, lack of rewards, unrealistic expectations, education and lack of trust were the top 10 factors influencing knowledge sharing proposed by the literature, which were confirmed by this research study. Additional factors extracted from interviews that enhanced literature include recognition, environment, selfishness, work overload, competition, race and physical distance.

As shown in Table 2, job security, at $65 \%$, was rated the highest factor contributing to knowledge sharing. Biggam (2002) and Keyes (2008) in their studies confirm that people want to own their knowledge for their job security. As a result, companies end up spending significant amounts of money to train new staff when employees retire or resign. In addition, motivation (61\%), lack of time (56\%), psychological factors $(56 \%)$, lack of communication $(54 \%)$, resistance to change (54\%) and lack of reward (51\%) arose as dominant factors contributing to factors influencing knowledge sharing. The importance of these factors were confirmed by the studies of Biggam (2002), Riege (2005), Keyes (2008), Jinming and Yuntao (2011), Kukko and Helander (2012), Malin (2012), Murtadho (2012) and Chatterjee (2014). Software developing organisations are advised - at the very least - to consider and address the top 10 factors exhibited in Table 2 to enhance the success of their projects. In addition to factors perceived as important by questionnaire respondents, factors influencing knowledge sharing obtained through interviews include recognition, environment, selfishness, work overload, competition, race and physical distance. Table 3 shares the interview questions, participants' responses and the researcher's interpretation and analysis.

\section{Responses from some of the respondents}

Below are some of the responses from the respondents:

'We are given too much work and we are expected to deliver within a short period of time, and therefore I don't have time to sit down with someone and assist'. [B Tech IT, Male, Developer]

'If you have a skill that no one else knows, why do you have to share it? because you can make a living out of it even after retirement, you can be a consultant'. [MSc IS, Female, Business Analyst]

'I can only share what I am paid for, whatever I know I own it' [B Tech IT, Male, Developer]

'Top managers don't care, then why should I care?'. [N Dip IT, Male, Developer]

'I have been good to everyone by sharing my skills and knowledge as it was the culture of my previous organisation but I have realised that in this organisations is every man for himself, now I have changed and I stopped sharing like everyone else'. [N Dip IT, Male, System Tester]

\section{Test of association}

Pearson's chi-squared test was used to test the association between pairs of categorical variables. Interpretation was performed at 0.05 cut-off for error rate. Figure 2 summarises

TABLE 3: Factors influencing knowledge sharing extracted from interviews.

\begin{tabular}{|c|c|c|}
\hline Interview question & Participants' responses & Researcher's interpretation and analysis \\
\hline $\begin{array}{l}\text { What factors contribute towards knowledge sharing in } \\
\text { your organisation? }\end{array}$ & $\begin{array}{l}\text { - Remuneration or rewards or promotions } \\
\text { - Lack of time } \\
\text { - Environment } \\
\text { - Project management } \\
\text { - Recognition }\end{array}$ & $\begin{array}{l}\text { - Employees do not share knowledge because they are not } \\
\text { rewarded or remunerated. } \\
\text { - Some do not share because the environment is not } \\
\text { conducive for knowledge sharing. } \\
\text { - Some factors include lack of time and discrimination. } \\
\text { - Employees are overloaded with tasks and find no time to } \\
\text { share their knowledge with others. } \\
\text { - If people are not respected and just undermined, they } \\
\text { find no interest in sharing what they know because they } \\
\text { are not valued. }\end{array}$ \\
\hline $\begin{array}{l}\text { What obstacles are there to knowledge sharing in your } \\
\text { organisation? }\end{array}$ & $\begin{array}{l}\text { - Lack of knowledge sharing structure } \\
\text { - Selfishness } \\
\text { - Job security } \\
\text { - Promotion } \\
\text { - Physical distance } \\
\text { - Ro systems or skills or knowledge documentation } \\
\text { - Level of knowledge (Juniors vs. seniors) } \\
\text { - Competition } \\
\text { - No time } \\
\text { - Work overload }\end{array}$ & $\begin{array}{l}\text { - It is very clear from the responses, that there are hefty } \\
\text { obstacles to knowledge sharing, mentioned multiple } \\
\text { times. These obstacles, for example, selfishness, job } \\
\text { security, race, competition and lack of time, demand } \\
\text { serious attention. } \\
\text { - Some people are just selfish and are in competition with } \\
\text { others forgetting that for a project to be successful, team } \\
\text { work is required. } \\
\text { - People from different geographical areas always find it } \\
\text { difficult to share their knowledge. }\end{array}$ \\
\hline $\begin{array}{l}\text { From the obstacles to knowledge sharing in your } \\
\text { organisation, how do you think these can be minimised? }\end{array}$ & $\begin{array}{l}\text { - Awareness or letting employees know and understand } \\
\text { the importance of knowledge sharing } \\
\text { - Training on knowledge sharing } \\
\text { - Finances (tools to share knowledge) } \\
\text { - Change views of employees who have a problem in } \\
\text { sharing knowledge } \\
\text { - Encourage sharing } \\
\text { - Empower people educationally } \\
\text { - Motivation } \\
\text { - Recognition: People want to be recognised } \\
\text { - Understanding of employees demands } \\
\text { - Best projects reward } \\
\text { - On-the-spot reward }\end{array}$ & $\begin{array}{l}\text { - Organisations should consider the solutions that can be } \\
\text { employed to minimise obstacles to knowledge sharing. } \\
\text { - Organisations should let their employees be aware of the } \\
\text { importance of knowledge sharing. } \\
\text { - There should be training and workshops to encourage } \\
\text { knowledge sharing culture. } \\
\text { - People should be empowered through education and be } \\
\text { motivated to further their studies. } \\
\text { - It is always said that motivated and recognised } \\
\text { employees always perform better. } \\
\text { Enough time must be allocated for teams to share their } \\
\text { knowledge, new skills and ways of performing tasks. } \\
\text { - People must be motivated by top management to share } \\
\text { knowledge; this can be performed using rewards based } \\
\text { on the success of projects or best projects. }\end{array}$ \\
\hline
\end{tabular}




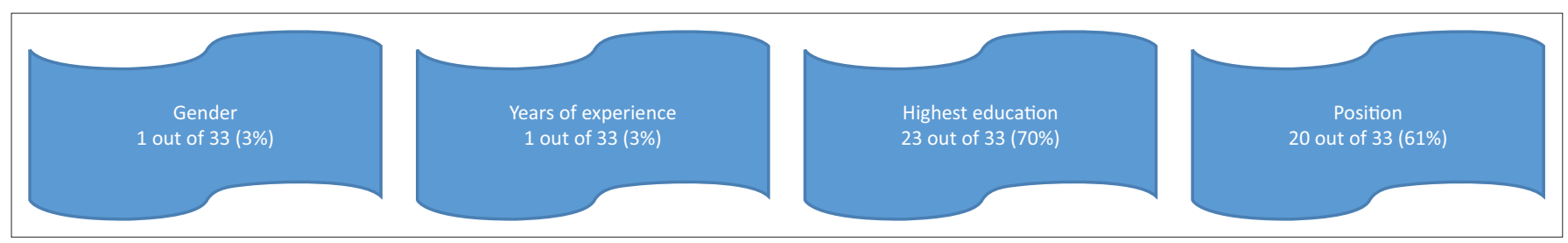

FIGURE 2: Number of variables demonstrating significant differences in responses per demographic group.

the number of variables per demographic variable that demonstrates significant association with the demographic variable $(p<0.05)$. It shows for each demographic variable the number (and overall percentage) out of the 33 variables that were tested where significant associations were found. $P$ values for highest education show the highest number of variables with significant associations: Most variables have a $P$ value of $<0.05$, which indicates that highest education is significantly associated with 23 out of the 33 items tested. Subsequently, it can be deduced that participants with differences in highest education level revealed significant differences in perceptions for a high number of variables. Similarly, $P$ values for position (role in organisation) show a high number of significant associations: 20 out of the 33 items tested have significant differences. With respect to years of experience, only one of the items tested has a significant association, which is 'no training'. The one variable with significant differences with regard to gender is education.

\section{Conclusion}

Obstacles to knowledge sharing present themselves at different levels in software developing organisations. There are obstacles in individual level, in organisational level and also in technological level. It is very clear from the research results that software developing organisations are facing serious challenges when it comes to knowledge sharing. These challenges are caused by the different factors as summarised in Tables 2 and 3. In some instances, all that is required for knowledge sharing may be motivation from top management. Rewards and salary reviews could play a major role in motivating employees to share knowledge. The research study and supporting literature suggest that software developing organisations are failing to meet customer expectations, not because they do not have the necessary knowledge, skills or expertise, but because they are not fully aware of the factors influencing the sharing of useful knowledge. The results from questionnaires indicate that job security, motivational factors, lack of time, physiological factors, lack of communication, resistance to change, lack of rewards, unrealistic expectations, education and lack of trust are major factors influencing knowledge sharing in software developing organisations. Additional factors originating from interviews include recognition, environment, selfishness, work overload, competition, race and physical distance. It is recommended that software developing organisations should work towards establishing a culture that is conducive for knowledge sharing and a situation where employees appreciate the link between knowledge sharing and project success. To mitigate some of these factors, it is recommended that sufficient time be provided to project team members to share knowledge, that employees be rewarded to avoid selfishness and that interracial relationships may require additional attention. Improved understanding of factors negatively influencing knowledge sharing is expected to assist software developing organisations in closing the gap for software development projects failing to meet the triple constraint of time, cost and scope. Recommendations for further research include a larger scale study investigating knowledge sharing in software developing organisations, investigating the links between knowledge sharing and organisational performance and a study investigating perceptions of different role players (e.g. project managers, business analysts and system testers) towards factors influencing knowledge sharing.

\section{Acknowledgements}

The authors would like to thank the Tshwane University of Technology (TUT) and the National Research Foundation (NRF) for their financial assistance.

\section{Competing interests}

The authors declare that they have no financial or personal relationships that may have inappropriately influenced them in writing this article.

\section{Authors' contributions}

L.T.K. was responsible for writing the full article and A.B.P. was responsible for supervising, mentoring me in writing the article before submitting.

\section{References}

Alony, I. \& Whymark, G., 2006, Developing a conceptual model for knowledge sharing Transformational tools for the 21st century TT211C2006, Central Queensland Transformational tools for the
University Press, Rockhampton.

Andrawina, L., 2009, 'Relationship between knowledge sharing and absorptive capacity moderated by organisational and technology factors: A conceptual model', paper presented at the IEEE International Conference, Hong Kong, 8-11th December, viewed 29 October 2016, from http:// ieeexplore iee.org/search/searchresult.jsp?newsearch=true\&queryText=Relatio ieeexplore ieee.org/search/searchresult.jsp?newsearch=true\&query Text=Relatio
nship $\% 20$ between $\% 20$ knowledge $\% 20$ sharing $\% 20$ and $\% 20$ absorptive $\% 20$ nship $\% 20$ between $\% 20$ knowledge $\% 20$ sharing $\% 20$ and $\% 20$ absorptive $\% 20$
capacity $\% 20$ moderated $\% 20$ by $\% 20$ organisational $\% 20$ and $\% 20$ technology $\% 20$ factors

Biggam, J., 2002, 'Exploiting soft systems methodology (SSM) and knowledge types to facilitate knowledge capture issues in a web site environment', paper presented at the 35th Hawaii International Conference on Systems Sciences, Glasgow, 7-10th the 35th Hawaii International Conference on Systems Sciences, Glasgow, 7-10th
January, viewed 29 October 2016, from http://ieeexplore.ieee.org/ document/994198/

Chatterjee, S., 2014, 'Managing constraints and removing obstacles to knowledge management', Journal of Knowledge Management 12(4), 24-38, viewed 16 February 2015, from https://mpra.ub.uni-muenchen.de/57789/

Cuellar, M.J., 2010, 'Assessing project success: Moving beyond the triple constraint', paper presented at the 5th International Research Workshop on Information Technology Project Management, St. Louis, MO, 11th December, viewed 29 October 2016, from http://aisel.aisnet.org/irwitpm2010/13/ 
Field, A., 2005, Discovering statistics using SPSS, 2nd edn., Sage, London.

George, D. \& Mallery, P., 2003, SPSS for windows step by step: A simple guide and reference, 4th edn., Allyn \& Bacon, Boston, MA.

Ghobadi, S., 2015, 'What drives knowledge sharing in software development teams: A literature review and classification framework', Information and Managemen 52(1), 82-97. https://doi.org/10.1016/j.im.2014.10.008

Ghobadi, S. \& D'Ambra, J., 2012, 'Knowledge sharing in cross-functional teams: A competitive model', Journal of Knowledge Management 16(2), 285-301. https:// doi.org/10.1108/13673271211218889

Ghobadi, S. \& Mathiassen, L., 2015, 'Perceived barriers to effective knowledge sharing in agile software teams', Information Systems Journal 26(2), 1-31, viewed 16 October 2016, from http://onlinelibrary.wiley.com/doi/10.1111/isj.12053/full

Ghobadi, S. \& Mathiassen, L., 2016, 'A model for assessing and mitigating knowledge sharing risks in agile software development'. Information Systems Journal 1-33, viewed 24 November 2016, from http://onlinelibrary.wiley.com/doi/10.1111/isj.12117/full

Greasley, P., 2008, Quantitative data analysis using SPSS: An introduction for health and social science, 1st edn., McGraw, New York.

Hans, R.T. \& Rwelamil, M.D., 2012, 'Knowledge based of project managers in the South African ICT sector', International Journal of Computer Science and Information Technology 2012(4), 455-478.

Hase, S., Sankaran, S. \& Davies, A., 2006, 'Overcoming barriers to knowledge management: Visiting the dark side of organisations', ACctKM Online Journal of Knowledge Management 3(1), 36-44, viewed 02 May 2015, from http://epubs. scu.edu.au/gcm_pubs/107/

Jari, S., Timo, M. \& Vesa, T., 2007, 'Managing and processing knowledge sharing between software organisations', paper presented at the Portland International Centre on Management of Engineering and Technology, Portland, 5-9th August, viewed 29 October 2016, from http://ieeexplore.ieee.org/stamp/stamp.jsp?arnumber $=4349432$

Jashapara, A., 2011, Knowledge management: An integrated approach, 2nd edn., Pearson Education, Harlow, Essex.

Jinming, F. \& Yuntao, C., 2011, 'Analysis on influence factors of enterprise knowledge sharing', paper presented at the International Conference of Computer Science and Service, Nanjing, 27-29th June, viewed 29 October 2016, from http:// ieeexplore.iee.org/document/5974367/

Juan, M., Rong, D., Song, M. \& Weili, Z., 2009, 'Factors affecting knowledge sharing in governmental fiscal departments: An empirical study', paper presented at the
16th International Conference on Industrial Engineering and Engineering Management, Beijing, 21-23rd October, viewed 29 October 2016, from http:// Management, Beijing, 21-23rd October,

Keyes, J., 2008, Identifying the barriers to knowledge sharing in knowledge intensive organisations, 1st edn., Prescott Valley, AZ, Northcentral University.

Killingsworth, B., Yajiong, X. \& Yongjun, L., 2016, 'Factors influencing knowledge sharing among global virtual teams', An International Journal of Team Performance Management 22(5 \& 6), 284-300, viewed 29 October 2016, from http://www. emeraldinsight.com/doi/full/10.1108/TPM-10-2015-0042

Kline, P., 1999, The handbook of psychological testing, 2nd edn., Routledge, London.

Kukko, M. \& Helander, N., 2012, 'Knowledge sharing barriers in growing software companies', paper presented at the 45th Hawaii International Conference on Systems Sciences, Maui, 4-7th January, viewed 29 October 2016, from http:// ieeexplore.ieee.org/document/6149351/
Malin, O., 2012, 'Managing knowledge sharing in software development organisations', Master's thesis, Linköping University, Sweden.

Mansooreh, Z., Mojtaba, S. \& Muhammad A.B., 2016, 'A systematic review of knowledge sharing challenges and practices in global software development', International Journal of Information Management 36(6), 995-1019. https://doi. org/10.1016/j.ijinfomgt.2016.06.007

Min, R., He, J. \& Gan, J., 2010, 'An analysis of knowledge sharing within organisation based on the psychological contract', paper presented at the 17th Internationa Conference of the Industrial Engineering and Engineering Management, Xiamen 29-31st October, viewed 29 October 2016, from http://ieeexplore.ieee.org/ document/5646100/

Mkhize, P.L., 2015, 'A knowledge sharing framework in the South African public sector', South African Journal of Information Management 17(1), 1-10. https:// doi.org/10.4102/sajim.v17i1.620

Mohammad, A.R. \& Rajib, A., 2014, 'Knowledge sharing in distributed agile projects: Techniques, strategies and challenges', paper presented at the 2014 Federal Conference on Computer Science and Information Systems, Warsaw, 7-10th September, viewed 29 October 2016, from http://ieeexplore.ieee.org/ document/6933185/

Murtadho, A., 2012, 'Knowledge management application system implementation in global energy company: Opentext 9.7.1 livelink global exploitation', paper presented at the 2012 International Conference of the Advanced Compute Science and Information Systems, Depok, 1-2nd December, viewed 29 Octobe 2016, from http://ieeexplore.ieee.org/document/6468728/

Park, J.G. \& Lee, J. 2014, 'Knowledge sharing in information systems development projects: Explicating the role of dependence and trust', International Journal of Project Management 32(1), 153-165. https://doi.org/10.1016/j.ijproman.2013. 02.004

Paulin, D. \& Suneson, K., 2012, 'Knowledge transfer, knowledge sharing and knowledge barriers - Three blurry terms in km', Electronic Journal of Knowledge Management 10(1), 81-91, viewed 02 May 2015, from http://publications.lib.chalmers.se/ publication/156127-knowledge-transfer-knowledge-sharing-and-knowledgebarriers-three-blurry-terms-in-km

Riege, A., 2005, 'Three-dozen knowledge-sharing barriers managers must consider', Journal of Knowledge Management 9(3), 18-35. https://doi.org/10.1108/ 13673270510602746

Soinil, J., Makinen, T. \& Tenhunen, V., 2007, 'Managing and processing knowledge sharing between software organisations: A case study', paper presented at the Portland International Center for Management of Engineering and Technology Conference, Portland, OR, 5-9th August, viewed 29 October 2016, from http:// ieeexplore.iee.org/document/4349432/

Willems, R., 2009, 'Knowledge sharing and retention through the use of collaborative software', Bachelor's thesis, Radboud University Nijmegen, the Netherlands.

Zhang, X. \& Jiang, Y., 2012, 'Who shall I share my knowledge with?: A receiver perspective of knowledge sharing behaviour', paper presented at the 2012 IEEE ICMIT, Sanur Bali, 11-13th June, viewed 29 October 2016, from http://ieeexplore. ieee.org/document/6225875/

Zhang, L., Yezhuang, T. \& Zhongying, Q., 2006, 'A conceptual model of organisation learning based on knowledge sharing', paper presented at the Sixth
International Conference on Advanced Learning Technologies, Washington, International Conference on Advanced Learning Technologies, Washington,
DC, 5-7th July, viewed 29 October 2016, from http://ieeexplore.ieee.org/ DC, 5-7th July, viewed
document/1652349/ 